University of Wollongong

Research Online

Australian Institute for Innovative Materials -

Papers

Australian Institute for Innovative Materials

$1-1-2014$

Thermoelectric performance of n-Type (PbTe)0.75(PbS)0.15(PbSe) 0.1 composites

\author{
Sima Aminorroaya Yamini \\ University of Wollongong, sima@uow.edu.au \\ Heng Wang \\ California Institute of Technology \\ Dianta Ginting \\ University of Wollongong, dg482@uowmail.edu.au \\ David R. G Mitchell \\ University of Wollongong, dmitchel@uow.edu.au \\ S X. Dou \\ University of Wollongong, shi@uow.edu.au
}

See next page for additional authors

Follow this and additional works at: https://ro.uow.edu.au/aiimpapers

Part of the Engineering Commons, and the Physical Sciences and Mathematics Commons

Research Online is the open access institutional repository for the University of Wollongong. For further information contact the UOW Library: research-pubs@uow.edu.au 


\title{
Thermoelectric performance of n-Type (PbTe)0.75(PbS)0.15(PbSe)0.1 composites
}

\author{
Abstract \\ Lead chalcogenides ( $\mathrm{PbQ}, \mathrm{Q}=\mathrm{Te}, \mathrm{Se}, \mathrm{S})$ have proved to possess high thermoelectric efficiency for both $\mathrm{n}$ - \\ type and p-type compounds. Recent success in tuning of electronic band structure, including \\ manipulating the band gap, multiple bands, or introducing resonant states, has led to a significant \\ improvement in the thermoelectric performance of $\mathrm{p}$-type lead chalcogenides compared to the $n$-type \\ ones. Here, the n-type quaternary composites of (PbTe)0.75(PbS) $0.15(\mathrm{PbSe}) 0.1$ are studied to evaluate \\ the effects of nanostructuring on lattice thermal conductivity, carrier mobility, and effective mass \\ variation. The results are compared with the similar ternary systems of $(\mathrm{PbTe}) 1-\mathrm{x}(\mathrm{PbSe}) \mathrm{x},(\mathrm{PbSe})$ \\ $1-\mathrm{x}(\mathrm{PbS}) \mathrm{x}$, and $(\mathrm{PbS}) 1-\mathrm{x}(\mathrm{PbTe}) \mathrm{x}$. The reduction in the lattice thermal conductivity owing to phonon \\ scattering at the defects and interfaces was found to be compensated by reduced carrier mobility. This \\ results in a maximum figure of merit, $\mathrm{zT}$, of $\sim 1.1$ at $800 \mathrm{~K}$ similar to the performance of the single phase \\ alloys of $\mathrm{PbTe}, \mathrm{PbSe}$, and (PbTe) 1-x(PbSe)x.
}

\section{Keywords}

pbte, pbse, type, $1,75, \mathrm{n}$, pbs, performance, thermoelectric, composites, 15

\section{Disciplines}

Engineering | Physical Sciences and Mathematics

\section{Publication Details}

Yamini, S. Aminorroaya., Wang, H., Ginting, D., Mitchell, D. R. G., Dou, S. Xue. \& Snyder, G. Jeffrey. (2014). Thermoelectric performance of n-Type (PbTe)0.75(PbS)0.15(PbSe)0.1 composites. ACS Applied Materials and Interfaces, 6 (14), 11476-11483.

\section{Authors}

Sima Aminorroaya Yamini, Heng Wang, Dianta Ginting, David R. G Mitchell, S X. Dou, and G. Jeffrey Snyder 


\section{Thermoelectric Performance of $n$-Type}

\section{$(\mathrm{PbTe})_{0.75}(\mathrm{PbS})_{0.15}(\mathrm{PbSe})_{0.1}$ Composites}

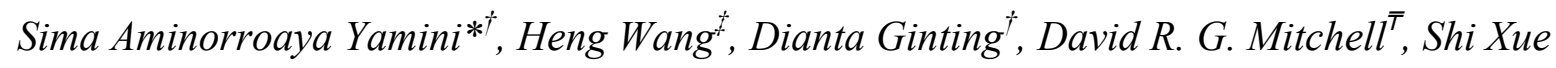
Dou $^{\dagger}$, G Jeffrey Snyder $*^{*} \|$

${ }^{\dagger}$ Australian Institute for Innovative Materials, University of Wollongong, Innovation Campus, North Wollongong, NSW, 2519, Australia

${ }^{\ddagger}$ Materials Science, California Institute of Technology, Pasadena, CA 91125, USA.

${ }^{\bar{\top}}$ Electron Microscopy Centre, Australian Institute for Innovative Materials, University of Wollongong, Innovation Campus, North Wollongong, NSW, 2519, Australia

"ITMO University, Saint Petersburg, Russia

KEYWORDS. Quaternary $\mathrm{Pb}$ chalcogenides, n-type, composite, thermoelectric, mobility, thermal conductivity.

ABSTRACT. Lead chalcogenides $(\mathrm{PbQ}, \mathrm{Q}=\mathrm{Te}, \mathrm{Se}, \mathrm{S})$ have proved to possess high thermoelectric efficiency for both $n$-type and $p$-type compounds. Recent success in tuning of electronic band structure, including manipulating the band gap, multiple bands or introducing resonant states have led to a significant improvement in the thermoelectric performance of $p$ type lead chalcogenides compared to the $n$-type ones. Here, the $n$-type quaternary composites of $(\mathrm{PbTe})_{0.75}(\mathrm{PbS})_{0.15}(\mathrm{PbSe})_{0.1}$ are studied to evaluate the effects of nanostructuring on lattice thermal conductivity, carrier mobility and effective mass variation. The results are compared 
with the similar ternary systems of $(\mathrm{PbTe})_{1-\mathrm{x}}(\mathrm{PbSe})_{\mathrm{x}},(\mathrm{PbSe})_{1-\mathrm{x}}(\mathrm{PbS})_{\mathrm{x}}$ and $(\mathrm{PbS})_{1-\mathrm{x}}(\mathrm{PbTe})_{\mathrm{x}}$. The reduction in the lattice thermal conductivity owing to phonon scattering at the defects and interfaces was found to be compensated by reduced carrier mobility. This results in a maximum figure of merit, zT, of $\sim 1.1$ at $800 \mathrm{~K}$ similar to the performance of the single phase alloys of $\mathrm{PbTe}, \mathrm{PbSe}$ and $(\mathrm{PbTe})_{1-\mathrm{x}}(\mathrm{PbSe})_{\mathrm{x}}$.

\section{INTRODUCTION}

A long-standing technological challenge to the widespread application of thermoelectric generators for waste heat recovery is obtaining high performance thermoelectric materials from abundant elements. ${ }^{1-2}$ The energy conversion efficiency of thermoelectric materials is determined by the dimensionless figure of merit, $z T=\mathrm{S}^{2} T \sigma /\left(\kappa_{\mathrm{E}}+\kappa_{\mathrm{L}}\right)$, where $\mathrm{S}$ is the Seebeck coefficient, $\sigma$ is the electrical conductivity, $\mathrm{T}$ is the absolute temperature, and $\kappa_{\mathrm{L}}$ and $\kappa_{\mathrm{E}}$ are the lattice and electronic thermal conductivity, respectively. The search for high efficiency bulk thermoelectric materials for waste heat recovery has driven scientific interest on the mid-range temperature $(500-900 \mathrm{~K})$ thermoelectric materials, ${ }^{3-11}$ specifically PbTe-based alloys, which represent the highest thermoelectric conversion efficiencies among the existing thermoelectric materials for both $n$-type ${ }^{12-13}$ and $p$-type ${ }^{9,14}$ compounds. Recent success in tuning the electronic band structure near the Fermi level, including resonant states, ${ }^{6}, 15$ multiple bands ${ }^{14,}{ }^{16-19}$ and/or manipulating the band gap $^{20-24}$ results in a significant improvement in the thermoelectric performance $(z \mathrm{~T}=\sim 1.8)$ of $p$-type lead chalcogenides. On the other hand, the highest thermoelectric efficiency of $\sim 0.8^{25-26}$ has been achieved for $n$ type single phase $\mathrm{PbS}, \sim 1.1^{27}$ for $n$-type nanostructured $\mathrm{PbS}$ by introducing secondary phase, and $\sim 1.2$ for $n$-type PbSe, ${ }^{27-29}$ ternary systems of $\mathrm{PbSe}-\mathrm{PbS}^{30}$ and PbTe-PbSe. ${ }^{31}$ Therefore, it is still a big challenge to find an $n$-type $\mathrm{Pb}$-chalcogenide compounds that can provide a high $z T$ over a wide temperature range. 
Recent studies ${ }^{7}, 9,19,26,32$ have considered nanostructuring of bulk $\mathrm{Pb}$ chalcogenide compounds a viable approach to enhance the thermoelectric efficiency. This occurs through the reduction in lattice thermal conductivity which originates from phonon scattering at the interfaces of secondary phases. In a recent report, ${ }^{33}$ we have fabricated $p$-type bulk quaternary $\mathrm{Pb}$-chalcogenide composites through $\mathrm{PbS}$ alloying beyond its solubility limit in the single phase $(\mathrm{PbTe})_{0.9}(\mathrm{PbSe})_{0.1}$ matrix and shown that the $(\mathrm{PbTe})_{0.75}(\mathrm{PbS})_{0.15}(\mathrm{PbSe})_{0.1}$ composite represents the minimum thermal conductivity among the $(\mathrm{PbTe})_{(0.9-}$ ${ }_{\mathrm{x})}(\mathrm{PbSe})_{0.1}(\mathrm{PbS})_{\mathrm{x}}(x=0,0.05,0.1,0.15,0.2$ and 0.25$)$ compounds. Here, we study the thermoelectric properties of $n$-type bulk $(\mathrm{PbTe})_{0.75}(\mathrm{PbS})_{0.15}(\mathrm{PbSe})_{0.1}$ composites that were doped with $\mathrm{PbCl}_{2}$ to achieve various carrier concentrations. The results are compared with previous studies on $n$-type binary $\mathrm{PbS},{ }^{25} \mathrm{PbTe},{ }^{12,}{ }^{31} \mathrm{PbSe}^{28,34}$ and ternary sytems of PbTe$\mathrm{PbS}^{26}$ and $\mathrm{PbTe}-\mathrm{PbSe}^{31}$ in order to gain an understanding of the parameters that are influenced by simultaneous nanostructuring and solid solution and to provide insight into the fundamental issues regarding thermoelectric efficiency enhancement in $n$-type $\mathrm{Pb}$ chalcogenide compounds.

\section{EXPERIMENTAL}

Sample fabrication: Polycrystalline samples of $\mathrm{PbS}$ and $\mathrm{PbSe}$ were prepared by mixing high purity $\mathrm{Pb}(99.999 \%)$, Se (99.999\%), and dried S (99.9\%) in vacuum-sealed quartz ampoules at a residual pressure of $\sim 10^{-4}$ Torr. These were reacted at high temperature to produce high purity $\mathrm{PbSe}$ and $\mathrm{PbS}$ starting materials. The final polycrystalline $(\mathrm{PbTe})_{0.75}(\mathrm{PbS})_{0.15}(\mathrm{PbSe})_{0.1}$ samples were synthesized by mixing stoichiometric quantities of high purity $\mathrm{PbS}, \mathrm{PbSe}, \mathrm{Pb}$, and $\mathrm{Te}\left(99.999 \%\right.$ ), with $0.05,0.085,0.16,0.39 \mathrm{~mol} \% \mathrm{PbCl}_{2}$ added as the dopant. A total mass of $10 \mathrm{~g}$ was sealed in carbon-coated quartz tubes under vacuum, and then heated to $1373 \mathrm{~K}$ with a heating rate of $100 \mathrm{~K}$ per hour. After being held at $1323 \mathrm{~K}$ for 10 hours, the samples were quenched in cold water, followed by annealing at $773 \mathrm{~K}$ for 
48 hours. The resulting ingots from the synthesis procedure were hand-ground to powder with a mortar and pestle, and sintered at $773 \mathrm{~K}$ for 1 hour in a $12 \mathrm{~mm}$ diameter graphite mould, at an axial pressure of $40 \mathrm{MPa}$, achieved by induction hot pressing under an argon atmosphere. $^{35}$

Transport properties measurements: The resistivity and Hall coefficient were measured by loading the samples onto a heated $\mathrm{BN}$ substrate and attaching four probes to the edge of the sample. The sample was placed in vacuum in a magnetic field (up to $\pm 2 \mathrm{~T}$ ) perpendicular to its surface. The resistivity $(\rho)$ and Hall coefficient $\left(R_{\mathrm{H}}\right)$ (along the hot-pressing direction) were measured using the van de Pauw method. ${ }^{36}$ The Seebeck coefficients were measured using a Linseis LSR-3 instrument. The thermal conductivity $(\kappa)$ was calculated from $\kappa=$ $\rho D_{\mathrm{T}} C_{\mathrm{p}}$. The laser flash method (Linseis LFA 1000) was used to measure the thermal diffusivity $\left(D_{\mathrm{T}}\right)$, the density $(\rho)$ was calculated using the measured weight and dimensions, and the specific heat capacity $\left(\mathrm{C}_{\mathrm{p}}\right)$, was estimated by $C \mathrm{p}\left(k_{\mathrm{B}}\right.$ per atom $)=3.07+4.7 \times 10^{-4} \times$ ( $\mathrm{T} / \mathrm{K}-300)$. The combined uncertainty for all measurements involved in $z T$ determination is $\sim 20 \%$.

Materials characterisation: The crystallographic structure and composition were characterized by X-ray diffraction (XRD) using a PANalyticalX'Pert Pro X-Ray diffractometer using $\mathrm{Cu} \mathrm{K}$ radiation $(\lambda=1.544 \AA$, $40 \mathrm{kV}, 30 \mathrm{~mA})$. In order to measure the phase ratio and to calculate the lattice parameters, the X-ray diffraction patterns were refined using Rietveld analysis. Samples were characterized using a JEOL 2010 transmission electron microscope (TEM). TEM samples were prepared by producing $3 \mathrm{~mm}$ diameter discs using a Leica TXP polisher. They were ground and polished to less than $100 \mu \mathrm{m}$ in thickness, followed by dimpling and Ar-ion milling on a stage cooled with liquid nitrogen. During ion milling low voltages and currents were used to reduce damage on the samples. 


\section{RESULTS AND DISCUSSION}

Polycrystalline samples of $(\mathrm{PbTe})_{0.75}(\mathrm{PbS})_{0.15}(\mathrm{PbSe})_{0.1}$ were doped with $0.05,0.085,0.16$, $0.39 \mathrm{~mol} \% \mathrm{PbCl}_{2}$. The selected composition is located at the PbTe-rich side of the $\mathrm{PbTe}-$ $\mathrm{PbSe}-\mathrm{PbS}$ system, where the phase separation of face centred cubic (FCC) rock salt PbS-rich precipitates within the $\mathrm{PbTe}$-rich matrix occurs through the nucleation and growth process. ${ }^{24}$ 37-38 The XRD pattern in Figure 1(a) shows a low fraction of secondary phase in the PbTerich matrix. The crystal structure and lattice parameter of the matrix were determined by indexing the XRD pattern (Figure 1(a)) and employing Rietveld refinement. The measured lattice parameter of the matrix $(a=6.38 \AA)$ is smaller than for pure PbTe $(a=6.46 \AA)$. This can be attributed to the incorporation of selenium, $\mathrm{PbSe}(a=6.13 \AA)$, and/or sulphur, $\mathrm{PbS}(a$ $=5.93 \AA$ ), both of which have smaller lattice parameters than the PbTe matrix.

The transmission electron microscope (TEM) micrograph of the sintered sample in Figure 1(b) illustrates the morphology and distribution of precipitates $(100-200 \mathrm{~nm}$ in size) in the matrix. Electron diffraction analysis (not shown here) indicated that the matrix and precipitate exhibited a cube/cube orientation relationship. The lattice parameter of the $\mathrm{PbS}$ precipitates is about $7 \%$ smaller than that of the $\mathrm{PbTe}$ matrix. This lattice mismatch is sufficiently large that the interface is incoherent. This gives rise to moire fringes, which are visible at oblique interfaces between the two phases (Fig. 1b inset). Compositional analysis of the precipitates and matrix was performed using energy dispersive X-ray spectroscopy (EDS), by scanning transmission electron microscopy. Figures 1(c) shows spectra obtained from the matrix and the precipitate measured from adjacent regions of similar thickness. The precipitates are compositionally distinct from the matrix with almost no tellurium detected in the precipitate. The $\mathrm{Pb} \mathrm{M}$ line $(2.342 \mathrm{keV})$ and sulphur $\mathrm{K}$ line $(2.307 \mathrm{keV})$ overlap and this composite peak is much more intense for the $\mathrm{PbS}$ precipitate $(\mathrm{Pb}+\mathrm{S})$ compared with the matrix ( $\mathrm{Pb}$ only). Both phases contained selenium. These results are in good agreement with the XRD analysis which identified PbS-rich precipitates within PbTe-rich matrix. 
The samples were doped with $\mathrm{PbCl}_{2}$ in order to substitute divalent anions $\left(\mathrm{Te}^{2-}, \mathrm{Se}^{2-}, \mathrm{S}^{2-}\right)$ with monovalent $\mathrm{Cl}^{-}$anions. Every chlorine atoms introduces one electron to the conduction band. Iodine has proved to be an effective dopant for $\mathrm{PbTe}^{12}$ and $\mathrm{PbTe}-\mathrm{PbSe}$ alloys, ${ }^{31}$ whereas $\mathrm{Cl}$ performed more efficiently in $\mathrm{PbS}^{25}$ and $\mathrm{PbS}-\mathrm{PbTe}$ alloys ${ }^{26}$ due to the ionic radius mismatch between sulphur and iodine atoms in the lead sulfide lattice. The current compounds contain sulphur-rich secondary phases in the matrix, and Figure 1(d) shows good dopant efficiency, allowing control of the carrier concentrations up to $0.78 \% \mathrm{Cl}$, which corresponds to a Hall carrier concentration of $1 \times 10^{20} \mathrm{~cm}^{-3}$ at room temperature. The measured Hall carrier concentration $\left(n_{H}=1 / \mathrm{e} \cdot R_{H}\right)$ is in good agreement with the calculated carrier concentration according to the chlorine concentration.
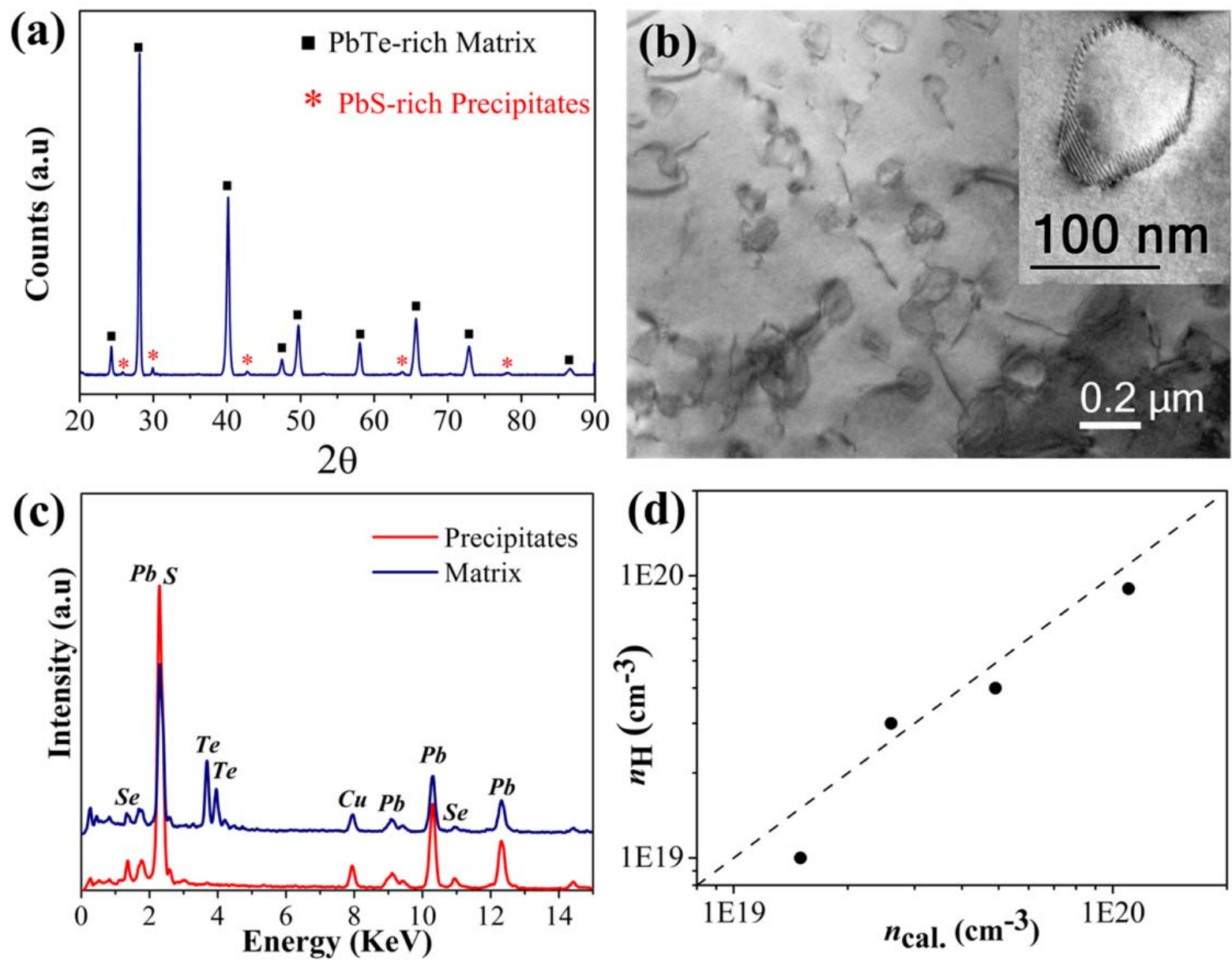

Figure 1. (a) Room temperature X-ray diffraction patterns for $(\mathrm{PbTe})_{0.75}(\mathrm{PbS})_{0.15}(\mathrm{PbSe})_{0.1}$ alloy, indicating PbS-rich secondary phase in the PbTe-rich matrix; (b) Bright field TEM 
micrograph of PbS-rich precipitates distributed within the PbTe-rich matrix of the sintered sample. Inset-detail of a precipitate showing moire fringes at oblique interfaces; (c) EDS spectra obtained from the matrix and precipitate. The precipitate contains almost no $\mathrm{Te} . \mathrm{Pb} \mathrm{M}$ and $\mathrm{S} \mathrm{K}$ line overlap occurs at $2.04 \mathrm{keV}$. This peak is more intense for the precipitate $(\mathrm{Pb}+\mathrm{S})$ compared with the matrix ( $\mathrm{Pb}$ only); (d) The measured Hall carrier concentration $\left(n_{H}=\right.$ 1/e. $R_{H}$ ) versus calculated value as a function of $\mathrm{Cl}$ concentration for Cl-doped $(\mathrm{PbTe})_{0.75}(\mathrm{PbS})_{0.15}(\mathrm{PbSe})_{0.1}$ alloys.

The electrical resistivity, Seebeck coefficient and total thermal conductivity of all the doped samples as a function of temperature in the range of 300-850 $\mathrm{K}$ are shown in Figure 2. The samples show the typical behaviour of degenerate semiconductors, with Seebeck coefficients and electrical resistivities increasing with temperature. However, for the slightly doped sample (9E18) deviation from this trend occurs at approximately $700 \mathrm{~K}$. The Hall carrier concentrations of this sample, shown in Figure 2(d), increases above $700 \mathrm{~K}$, indicative the bipolar effect, where the minority carriers (holes) contribute noticeably to the transport properties of the narrow band gap semiconductors. The highly doped samples show no sign of this bipolar effect which suggests that the single band assumption applies (within the carrier concentration and temperature ranges studied).

The band gap energy, $\mathrm{E}_{\mathrm{g}}$, at $0 \mathrm{~K}$ for $\mathrm{PbTe}, \mathrm{PbSe}$, and $\mathrm{PbS}$ is $0.19,0.17$, and $0.29 \mathrm{eV}$, respectively. ${ }^{39}$ There is an infinite solubility of $\mathrm{PbTe}-\mathrm{PbSe}$ and limited solubility of $\mathrm{PbS}$ in the PbTe phase. ${ }^{37}$ However, the variation of band gap at high temperature by alloying has not been studied. It has been assumed that the there is a linear correlation of band gap for solid solutions at a given temperature from the band gaps of the two constituents. The maximum solubility of $\mathrm{PbS}$ in a solid solution $(\mathrm{PbTe})_{0.9}(\mathrm{PbSe})_{0.1}$ is less than 10 at $\%^{24}$ and the temperature dependence of the direct energy gap for all chalcogenides $(\mathrm{PbTe}, \mathrm{PbSe}, \mathrm{PbS})$ is 
very similar, It has been determined experimentally to be approximately $3 \times 10^{-4} \mathrm{eVK}^{-1}$ up to $500 \mathrm{~K}$, while above that temperature the value is smaller. ${ }^{40}$ The predicted value of the band energy gap for the matrix of the quaternary compound reported here, will be $\sim 0.41 \mathrm{eV}$ at 700 K which appears to enough too narrow to avoid the bipolar effect for the low doped sample at high temperatures.
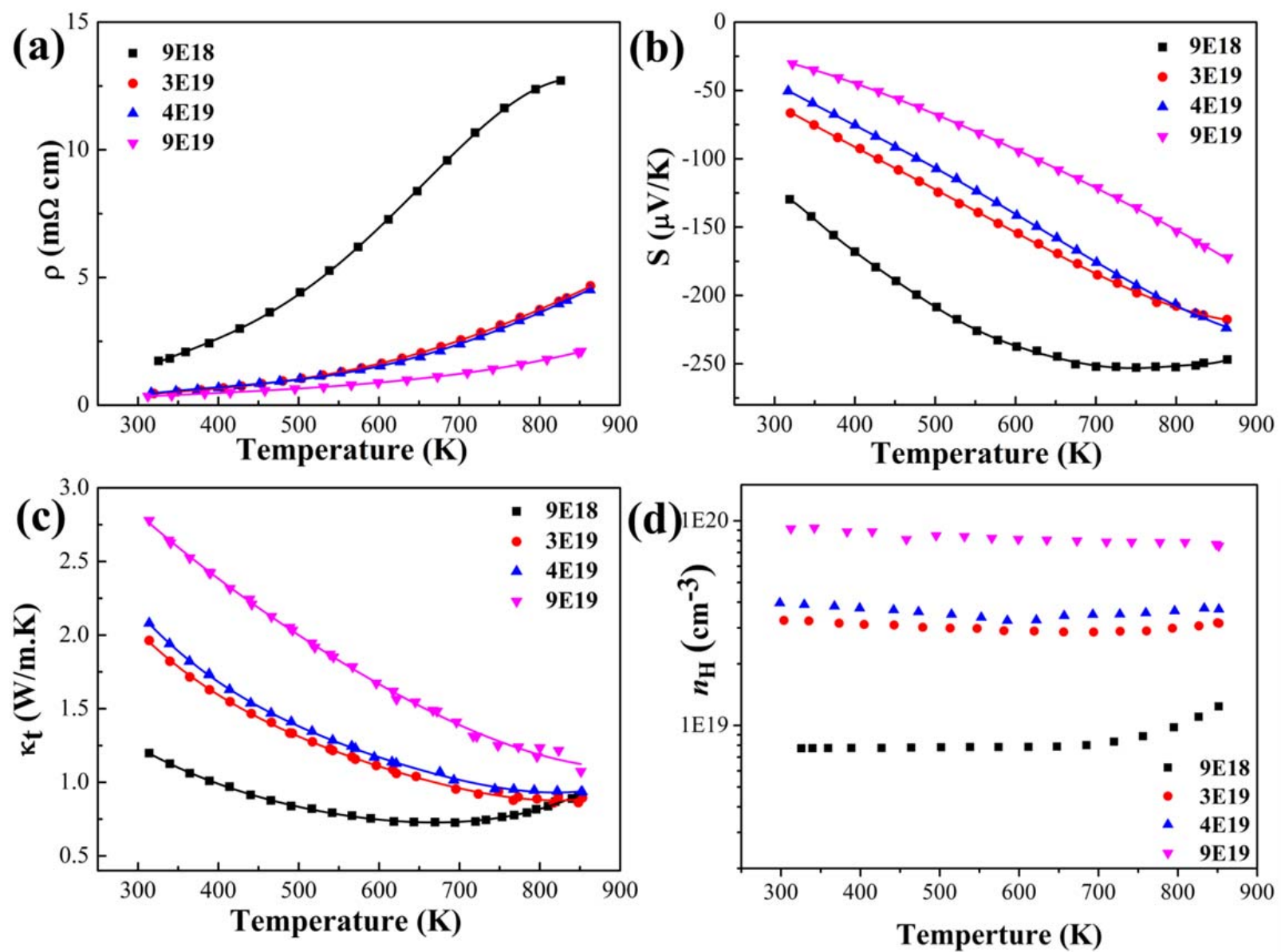

Figure 2. Thermoelectric transport properties of Cl-doped $(\mathrm{PbTe})_{0.75}(\mathrm{PbS})_{0.15}(\mathrm{PbSe})_{0.1}$ sintered bulk samples as a function of temperature, (a) electrical resistivity $(\mathrm{m} \Omega \cdot \mathrm{cm})$, (b) Seebeck coefficient $(\mu \mathrm{V} / \mathrm{K})$, (c) Total thermal conductivity $(\mathrm{W} / \mathrm{m} . \mathrm{K})$, (d) Hall carrier concentration $\left(\mathrm{cm}^{-3}\right)$.

$\kappa_{L}=\kappa-L T \sigma$ 
The lattice thermal conductivity, $\kappa_{L}$, of the composite (Figure 3(a)) was obtained by subtracting the electronic component, $\kappa_{e}$ from the total thermal conductivity. ${ }^{39,41}$ The value of the charge carrier thermal conductivity $\kappa_{e}$ can be determined via the Wiedemann-Franz relation, $\kappa \mathrm{e}=L T / \rho$, where $\rho$ is the resistivity and $L$ is the Lorenz number. Although the samples of the current study contain PbS-rich precipitates distributed within the matrix, it is reasonable to consider the matrix responsible for the electronic component of the thermal conductivity due to the small fraction of the secondary phase. The Lorenz number is estimated as a function of temperature, assuming a parabolic band with acoustic phonon scattering. ${ }^{42}$ The model employs the Fermi integral $F_{\mathrm{j} \text { : }}$

$$
F_{j}(\eta)=\int_{0}^{\infty} f \varepsilon^{j} d \varepsilon=\int_{0}^{\infty} \frac{\varepsilon^{j} d \varepsilon}{1+\exp (\varepsilon-\eta)}
$$

Where $\eta$ is the reduced chemical potential and calculated from the temperature dependent Seebeck value, S, through Equation 2:

$$
S=\frac{k}{e}\left(\frac{2 F_{1}(\eta)}{F_{0}(\eta)}-\eta\right)
$$

The $\eta$ values that fit the Equation 2 are used to calculate $L$ through Equation 3:

$$
L=\left(\frac{k}{e}\right) \frac{3 F_{0}(\eta) F_{2}(\eta)-4 F_{1}(\eta)^{2}}{F_{0}(\eta)^{2}}
$$

The lattice thermal conductivity of $\mathrm{PbS}$ is larger than both $\mathrm{PbSe}$ and $\mathrm{PbTe} .^{39}$ The current study composite of $(\mathrm{PbTe})_{0.75}(\mathrm{PbS})_{0.15}(\mathrm{PbSe})_{0.1}$ can be simplified as $\mathrm{PbTe}$ which is initially alloyed by $10 \mathrm{at} \% \mathrm{PbSe}$ to form a solid solution parent compound of $(\mathrm{PbTe})_{0.9}(\mathrm{PbSe})_{0.1}$. This is then further alloyed by $\mathrm{PbS}$ beyond its solubility limit (10 at $\%$ ) to form $\mathrm{PbS}$-rich precipitates within a matrix with chemical composition very close to $(\mathrm{PbTe})_{0.8}(\mathrm{PbS})_{0.1}(\mathrm{PbSe})_{0.1}{ }^{24}$ The lattice thermal conductivity of the current study composite, $(\mathrm{PbTe})_{0.75}(\mathrm{PbS})_{0.15}(\mathrm{PbSe})_{0.1}$, is compared to the lattice thermal conductivity of $n$-type ${ }^{31}$ and $p$ - 
type $\quad(\mathrm{PbTe})_{0.9}(\mathrm{PbSe})_{0.1},{ }^{24} \quad p$-type $\quad(\mathrm{PbTe})_{0.8}(\mathrm{PbSe})_{0.1}(\mathrm{PbS})_{0.1},{ }^{24} \quad n$-type $\quad \mathrm{PbS},{ }^{25}$ $(\mathrm{PbS})_{0.92}(\mathrm{PbTe})_{0.08}{ }^{26}$ and $(\mathrm{PbS})_{0.84}(\mathrm{PbTe})_{0.16}{ }^{26}$ in Figure 3(a). The significantly low lattice thermal conductivity obtained in the current study composite compared to that of the parent solid solution of $(\mathrm{PbTe})_{0.9}(\mathrm{PbSe})_{0.1}$ can be attributed to the scattering of phonons on randomly distributed solute atoms of sulphur in the matrix ${ }^{31,43}$ and/or scattering from interfaces and defects originated from distribution of precipitates within the matrix. In the following section these two effects are differentiated.

The calculated lattice thermal conductivity, $\kappa_{L}$, as a function of solid solution composition is summarised in Figure 3(b) for solid solution $\mathrm{PbTe}-\mathrm{PbSe}$ and $\mathrm{PbSe}-\mathrm{PbS}$ systems at room temperature and $800 \mathrm{~K}$ and $850 \mathrm{~K}$ respectively. The experimental and calculated $\kappa_{L}$ of single phase $\mathrm{PbTe}-\mathrm{PbSe}^{31}$ alloys indicate considerable reduction in room temperature $\kappa_{L}$ of $\mathrm{PbTe}$ from $\sim 2$ to $\sim 1.5 \mathrm{Wm}^{-1} \mathrm{~K}^{-1}$ for $n$-type $(\mathrm{PbTe})_{0.9}(\mathrm{PbSe})_{0.1}(\mathrm{PbTe}$ alloyed by 10 at $\% \mathrm{PbSe})$ and then gradually reduced to a minimum value of $\sim 1.3 \mathrm{Wm}^{-1} \mathrm{~K}^{-1}$ at 25 at $\% \mathrm{PbSe}$. This indicates a maximum $35 \%$ reduction in the lattice thermal conductivity of $\mathrm{PbTe}$ due to point defect scattering. The alloy scattering in the $\mathrm{PbTe}-\mathrm{PbSe}^{31}$ system results in less than $25 \%$ maximum reduction in $\kappa_{L}$ at $800 \mathrm{~K} .{ }^{31}$ Figure 3(a) shows that these results are in good agreement with $\kappa_{L}$ of $p$-type $(\mathrm{PbTe})_{0.9}(\mathrm{PbSe})_{0.1}$ alloy. $^{24,31}$

The $\kappa_{L}$ of solid solution $\mathrm{PbSe}-\mathrm{PbS}^{43}$ system (Figure 3(b)) shows similar behaviour to $\mathrm{PbTe}-\mathrm{PbSe}$ system. The 10 at $\% \mathrm{PbS}$ alloying reduces the $\kappa_{L}$ of $\mathrm{PbSe}$ by $\sim 15 \%$ to $1.4 \mathrm{Wm}^{-}$ ${ }^{1} \mathrm{~K}^{-1}$ at room temperature and 30 at $\% \mathrm{PbS}$ results in the maximum $30 \%$ reduction in $\kappa_{L}$ of $\mathrm{PbSe}$. The reduction in $\kappa_{L}$ of $\mathrm{PbSe}$ in solid solution $\mathrm{PbSe}-\mathrm{PbS}$ system at high temperature, $850 \mathrm{~K}$, is limited to less than $15 \% .{ }^{43}$ Considering the significant reduction in $\kappa_{L}$ of PbSe by alloying with $\mathrm{PbS}$, it is reasonable to assume that solute sulphur atoms in $(\mathrm{PbTe})_{0.9}(\mathrm{PbSe})_{0.1}$ alloy behave similarly to sulphur in $\mathrm{PbSe},{ }^{43}$ and therefore the $\kappa_{L}$ values for the composite in 
the present study are estimated to be no less than $\sim 1.5$ and $\sim 0.6$ at room temperature and 800 $\mathrm{K}$ respectively. These values are approximately $20 \%$ larger than the experimental values of $\kappa_{L}$ for $(\mathrm{PbTe})_{0.75}(\mathrm{PbS})_{0.15}(\mathrm{PbSe})_{0.1}$ in Figure 3(a). It suggests that distribution of secondary phase in the $(\mathrm{PbTe})_{0.75}(\mathrm{PbS})_{0.15}(\mathrm{PbSe})_{0.1}$ composite results in further reduction in the lattice thermal conductivity owing to scattering of phonons at boundaries and interfaces originated from distributed secondary phase sulphide. The nanostructured compounds of $(\mathrm{PbS})_{0.92}(\mathrm{PbTe})_{0.08}$ and $(\mathrm{PbS})_{0.84}(\mathrm{PbTe})_{0.16}{ }^{26}$ in Figure 3(a) show lower $\kappa_{L}$ than $\mathrm{PbS}$ in agreement with the current study results.
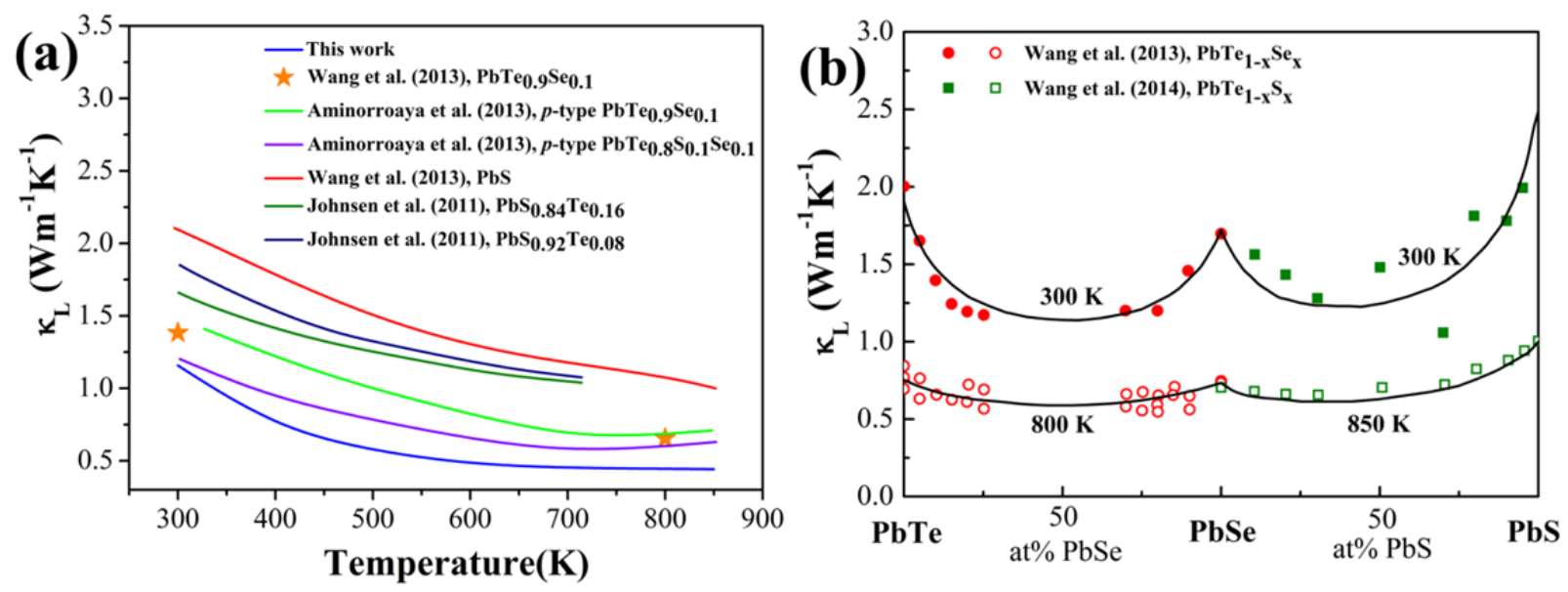

Figure 3. (a) Temperature dependence of the lattice thermal conductivity (W/m.K) of $n$-type $(\mathrm{PbTe})_{0.75}(\mathrm{PbS})_{0.15}(\mathrm{PbSe})_{0.1}$, compared to the lattice thermal conductivity of $n$-type $\mathrm{PbS},{ }^{25}$ $(\mathrm{PbTe})_{0.9}(\mathrm{PbSe})_{0.1},{ }^{31}(\mathrm{PbS})_{0.92}(\mathrm{PbTe})_{0.08}{ }^{26}(\mathrm{PbS})_{0.84}(\mathrm{PbTe})_{0.16}{ }^{26}$ and $p$-type $(\mathrm{PbTe})_{0.9}(\mathrm{PbSe})_{0.1}$ and $(\mathrm{PbTe})_{0.8}(\mathrm{PbSe})_{0.1}(\mathrm{PbS})_{0.1}{ }^{24}$ (b) The calculated lattice thermal conductivity as a function of solid solution composition.

The thermoelectric quality factor, $B$ was introduced by Chasmar and Stratton ${ }^{44-46}$ to define the merit of semiconducting compounds as thermoelectric materials through several fundamental parameters. 


$$
\begin{aligned}
& B=\left(k_{B} / e\right)^{2} \frac{\sigma_{0} T}{\kappa_{L}} \\
& \sigma_{0}=2 e \mu\left(\frac{2 \pi m^{*} k_{B} T}{h^{2}}\right)^{3 / 2}
\end{aligned}
$$

Where, $k_{B}$ and $h$ are the Boltzmann and Planck constants, respectively, and $\mu$ is the mobility. The low lattice thermal conductivity in nanostructured bulk thermoelectric materials is generally accompanied by low mobility, which arises from scattering of charge carriers. The measured Seebeck coefficient and Hall mobility for n-type $(\mathrm{PbTe})_{0.75}(\mathrm{PbS})_{0.15}(\mathrm{PbSe})_{0.1}$ composite as a function of carrier concentration at room temperature and $800 \mathrm{~K}$ are compared to those of $\mathrm{PbS},{ }^{25}, \mathrm{PbSe}^{28,}{ }^{34} \mathrm{PbTe},{ }^{12}$ $(\mathrm{PbSe})_{0.1}(\mathrm{PbTe})_{0.9},{ }^{31},(\mathrm{PbS})_{0.92}(\mathrm{PbTe})_{0.08}{ }^{26}(\mathrm{PbS})_{0.84}(\mathrm{PbTe})_{0.16}{ }^{26}$ in Figure 4. The decrease in the Seebeck coefficient with carrier concentration in Figure 4(a) confirms the single band transport model for all systems. The conduction band effective mass $\left(m^{*}\right)$ for this alloy ${ }^{42}$ is estimated from Equation 3, using $\eta$ from Equation 2, the temperature and the carrier concentration $\left(\mathrm{n}=1 / \mathrm{e} \cdot R_{H}\right)$ :

$$
n=4 \pi\left(\frac{2 m^{*} k_{B} T}{h^{2}}\right)^{3 / 2} F_{1 / 2}
$$

The model estimates the room temperature effective mass $\left(m^{*}\right)$ value of $0.29 m_{\mathrm{e}}$ that is higher than $0.25 m_{\mathrm{e}}$ for $\mathrm{PbTe},{ }^{35} 0.27 m_{\mathrm{e}}$ for $\mathrm{PbSe}^{28}$ and lower than $0.39 m_{\mathrm{e}}$ for PbS. ${ }^{25}$ The PbS-rich PbS-PbTe nanostructured composites have the effective mass of $0.41 m_{\mathrm{e}}$ for $(\mathrm{PbS})_{0.92}(\mathrm{PbTe})_{0.08}{ }^{26}$ and $0.42 m_{\mathrm{e}}$ for $(\mathrm{PbS})_{0.84}(\mathrm{PbTe})_{0.16},{ }^{26}$ which is similar to $\mathrm{PbS}\left(0.39 m_{\mathrm{e}}\right)$. Where the acoustic phonon scattering is dominant, which generally describes the scattering mechanism for good thermoelectric materials above room temperature, the mobility $(\mu)$ decreases with $m^{* 5 / 2}$. The charge carrier concentration-dependant Hall mobilities in Figure $4(\mathrm{~b}, \mathrm{c})$ indicate that the present compound has lower room temperature mobilty than $\mathrm{PbS}\left(\mathrm{m}^{*}\right.$ $\left.=0.39 m_{\mathrm{e}}\right)$, although it has a smaller effective mass $\left(m^{*}=0.29 m_{\mathrm{e}}\right)$. 
Figure 4(b) shows a Hall carrier mobility of roughly $345 \mathrm{~cm}^{2} \mathrm{~V}^{-1} \mathrm{~s}^{-1}$ for the doped $(\mathrm{PbTe})_{0.75}(\mathrm{PbS})_{0.15}(\mathrm{PbSe})_{0.1}$, which is lower than $\sim 600 \mathrm{~cm}^{2} \mathrm{~V}^{-1} \mathrm{~s}^{-1}$ for the parent compound of $(\mathrm{PbTe})_{0.9}(\mathrm{PbSe})_{0.1} .^{31}$ This can be attributed to scattering on randomly substituted soluble sulphur atoms in the matrix and/or contribution of precipitates. The composition dependent mobility shift of $\mathrm{PbTe}-\mathrm{PbSe}^{31}$ solid solution alloys in Figure 4(d) shows that the random substitution of selenium atoms $(\sim 5 \mathrm{at} \% \mathrm{PbSe})$ in $\mathrm{PbTe}$ reduces the room temperature carrier mobility of undoped PbTe from $\sim 1350$ to $\sim 1200 \mathrm{~cm}^{2} \mathrm{~V}^{-1} \mathrm{~s}^{-1}$ due to scattering of carriers from disordered atoms. Further alloying, gradually reduces the mobility to the minimum value of $\sim 780 \mathrm{~cm}^{2} \mathrm{~V}^{-1} \mathrm{~s}^{-1}$ at around $30 \mathrm{at} \% \mathrm{PbSe}^{31}$ producing a maximum reduction of $\sim 50 \%$. Likewise, the room temperature carrier mobility of PbSe reduced from $\sim 1300$ to $\sim 950 \mathrm{~cm}^{2} \mathrm{~V}^{-}$ ${ }^{1} \mathrm{~s}^{-1}$ when alloyed with 10 at $\% \mathrm{PbS}$ reaching a minimum value of $\sim 650 \mathrm{~cm}^{2} \mathrm{~V}^{-1} \mathrm{~s}^{-1}$ at around 30 at $\% \mathrm{PbS},{ }^{43}$ again producing a $50 \%$ reduction in mobility. The Hall mobility reduction due to disordered atoms at high temperatures $(800 \mathrm{~K})$ is roughly $30 \%$ for both solid solution of $\mathrm{PbTe}_{\mathrm{PbSe}}{ }^{31}$ and $\mathrm{PbSe}-\mathrm{PbS}^{43}$ systems.

Assuming a similar role for solute sulphur atoms in $(\mathrm{PbTe})_{0.9}(\mathrm{PbSe})_{0.1}$ compared with $\mathrm{PbSe}-\mathrm{PbS},{ }^{43}$ the carrier mobility of the matrix is estimated to be $\sim 440 \mathrm{~cm}^{2} \mathrm{~V}^{-1} \mathrm{~s}^{-1}$. This is higher than the measured value for the current study compound $\left(\sim 345 \mathrm{~cm}^{2} \mathrm{~V}^{-1} \mathrm{~s}^{-1}\right)$. The maximum reduction in carrier mobilities due to contribution of disorder in solid solution of $\mathrm{PbSe}_{-} \mathrm{PbS}^{43}$ and $\mathrm{PbTe}-\mathrm{PbSe}^{31}$ alloys is less than $50 \%$ which also confirms that the detected reduction in mobility of $(\mathrm{PbTe})_{0.75}(\mathrm{PbS})_{0.15}(\mathrm{PbSe})_{0.1}$ composite exceeds the contribution of solid solution atoms. Therefore, the increased number of interfaces and defects originated from distribution of precipitates within the matrix has raised the scattering of carriers and consequently lowered the charge carrier mobility.

As shown in Figure 4(d), despite the significant reduction in the mobility of PbSe by alloying with $\mathrm{PbS}$, the Hall mobility of $\mathrm{PbS}$ shows only an insignificant reduction through 
alloying with $\mathrm{PbSe}$ because the effective mass of the compound tends to decrease simultaneously and thus compensate for the mobility reduction by disordered atoms. ${ }^{43}$ The comparable effective masses of the binary PbTe $\left(0.25 m_{\mathrm{e}}\right)^{35}$ and $\mathrm{PbSe}\left(0.27 m_{\mathrm{e}}\right)^{28}$ compounds result in independence of the conduction band effective mass of the ternary $\mathrm{PbTe}-\mathrm{PbSe} \mathrm{e}^{31}$ alloys on composition. Whereas, there is approximately a linear relationship between the effective mass of $\mathrm{PbSe}-\mathrm{PbS}$ alloys and those of their constituents $\mathrm{PbS}\left(0.39 m_{\mathrm{e}}\right)$ and $\mathrm{PbSe}$ $\left(0.27 m_{\mathrm{e}}\right) .^{43}$ Similar behaviour is expected for $\mathrm{PbS}$ that is alloyed with $\mathrm{PbTe}$ up to its solubility limit $\left(<3\right.$ at $\left.\%{ }^{26}\right)$. The nanostructured $(\mathrm{PbS})_{0.92}(\mathrm{PbTe})_{0.08}{ }^{26}$ and $(\mathrm{PbS})_{0.84}(\mathrm{PbTe})_{0.16}{ }^{26}$ compounds in Figure 4(b) represent Hall mobilties slightly lower than the single phase $\mathrm{PbS}^{25}$ which also confirms the contribution of precipitates to Hall carrier mobility reduction.
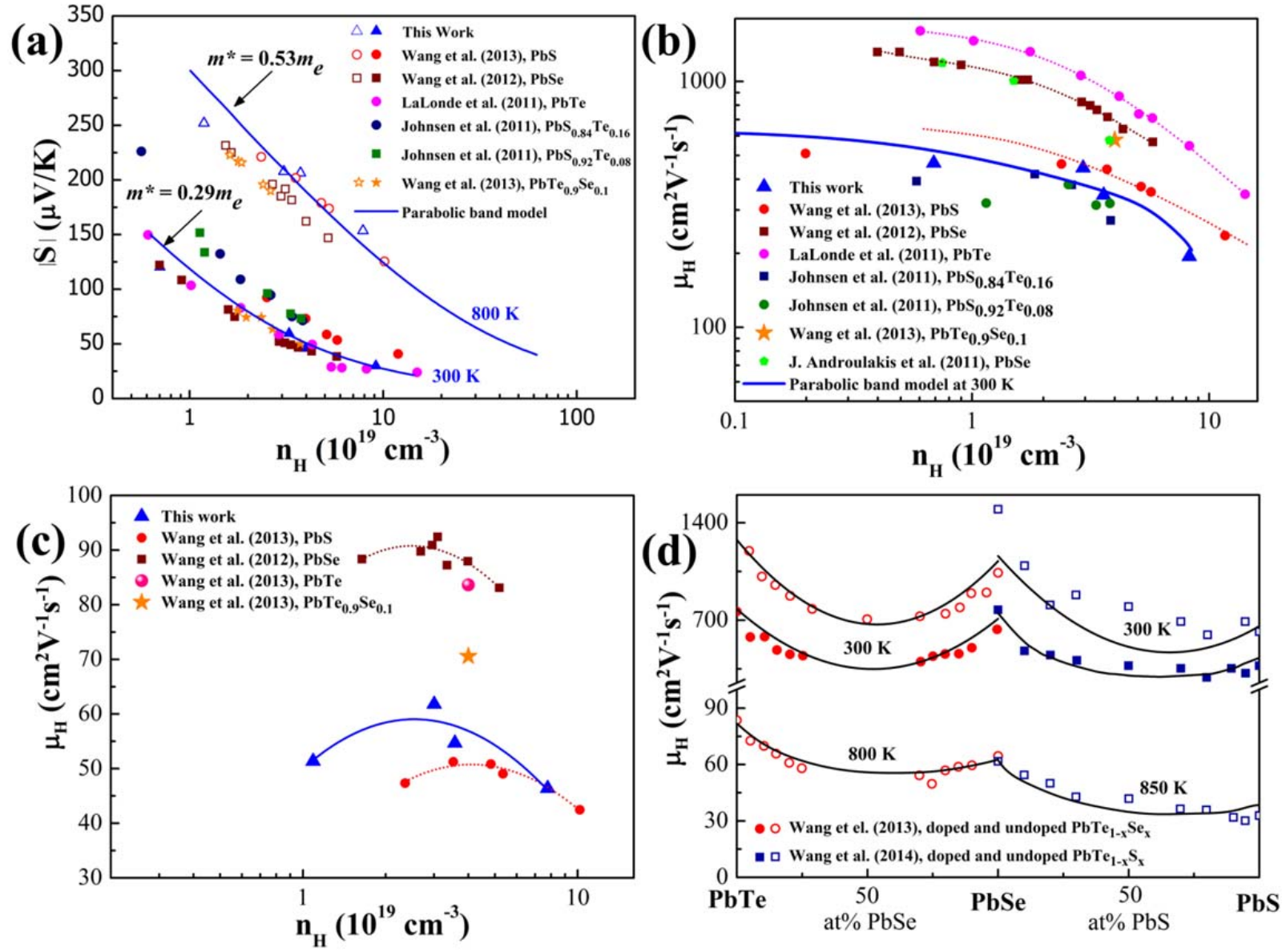

Figure 4. The Hall carrier concentration dependence of (a) room temperature Seebeck coefficient and Hall mobility of $n$-type $(\mathrm{PbTe})_{0.75}(\mathrm{PbS})_{0.15}(\mathrm{PbSe})_{0.1}$ (current study) compared 
to those reported in the literature, ${ }^{12,26,28,31,34}$ (b) at room temperature and (c) at $800 \mathrm{~K}$. The effective mass is estimated from the single parabolic band model; (d) The experimental and calculated mobility shift as a function of the solid solution composition for doped and undoped single phase alloys.

Despite a low lattice thermal conductivity, the quaternary compound of $(\mathrm{PbTe})_{0.75}(\mathrm{PbS})_{0.15}(\mathrm{PbSe})_{0.1}$ exhibits a low carrier mobility that has a negative impact on the thermoelectric quality factor. In order to indicate whether the reduction in the lattice thermal conductivity is able to compensate for the effect of low mobility on electronic properties, the thermoelectic figure of merit values for $n$-type $(\mathrm{PbTe})_{0.75}(\mathrm{PbS})_{0.15}(\mathrm{PbSe})_{0.1}$ composite samples are shown in Figure 5(a) and the $z \mathrm{~T}$ of the composite with $4 \times 10^{19} \mathrm{~cm}^{-3}$ carrier concentration from the current study is compared with the $z T$ values reported for $n$-type $\mathrm{PbS},{ }^{25} \mathrm{PbSe},{ }^{28}$ $\mathrm{PbTe}^{31}(\mathrm{PbTe})_{0.9}(\mathrm{PbSe})_{0.1},{ }^{31}(\mathrm{PbS})_{0.92}(\mathrm{PbTe})_{0.08}{ }^{26}$ and $(\mathrm{PbS})_{0.84}(\mathrm{PbTe})_{0.16}{ }^{26}$ at similar carrier concentration in Figure 5(b). The maximum $z T$ value of $\sim 1.1$ has been achieved at $750 \mathrm{~K}$ for the sample with $3 \times 10^{19} \mathrm{~cm}^{-3}$ carrier concentration. Figure 5(b) indicates that $\mathrm{PbTe}$ and PbSe-based alloys ${ }^{28,31,34}$ have figure of merits much higher than those of PbS-based compounds. $^{25-26}$ The composite in the current study demonstrates similar thermoelectric efficiency to $n$-type PbTe, ${ }^{31}$ the parent alloy of $(\mathrm{PbTe})_{0.9}(\mathrm{PbSe})_{0.1}{ }^{31}$ and $\mathrm{PbSe}^{28}$ The reduced lattice thermal conductivity of $n$-type $\mathrm{PbTe}-\mathrm{PbSe}$ solid solution alloys through phonon scattering on point defects is compensated by reduced mobility and results in similar $z \mathrm{~T}$ value over the whole composition range. ${ }^{31}$ Whereas, the figure of merit of $n$-type PbSe is reduced with increasing $\mathrm{PbS}$ fraction owing to enhanced effective mass. ${ }^{43}$ The current study compound of $(\mathrm{PbTe})_{0.75}(\mathrm{PbS})_{0.15}(\mathrm{PbSe})_{0.1}$ shows an effective mass of $\sim 0.29 \mathrm{~m}_{\mathrm{e}}$, being close to that of PbTe $\left(0.25 m_{\mathrm{e}}\right)$. While, the lattice thermal conductivity and the Hall carrier mobility are reduced due to scattering of phonons and charge carriers on solute atoms and secondary 
phase interfaces respectively. In contrast, a considerable reduction in lattice thermal conductivity due to the scattering of phonons at the secondary phase interfaces compensates the reduction in the mobility of carriers and the increased effective mass, and results in similar thermoelectric efficiency to $\mathrm{PbTe}, \mathrm{PbSe}$ and $\mathrm{PbTe}-\mathrm{PbSe}$ alloys, ${ }^{28,31,34}$ as shown in Figure 5(b).
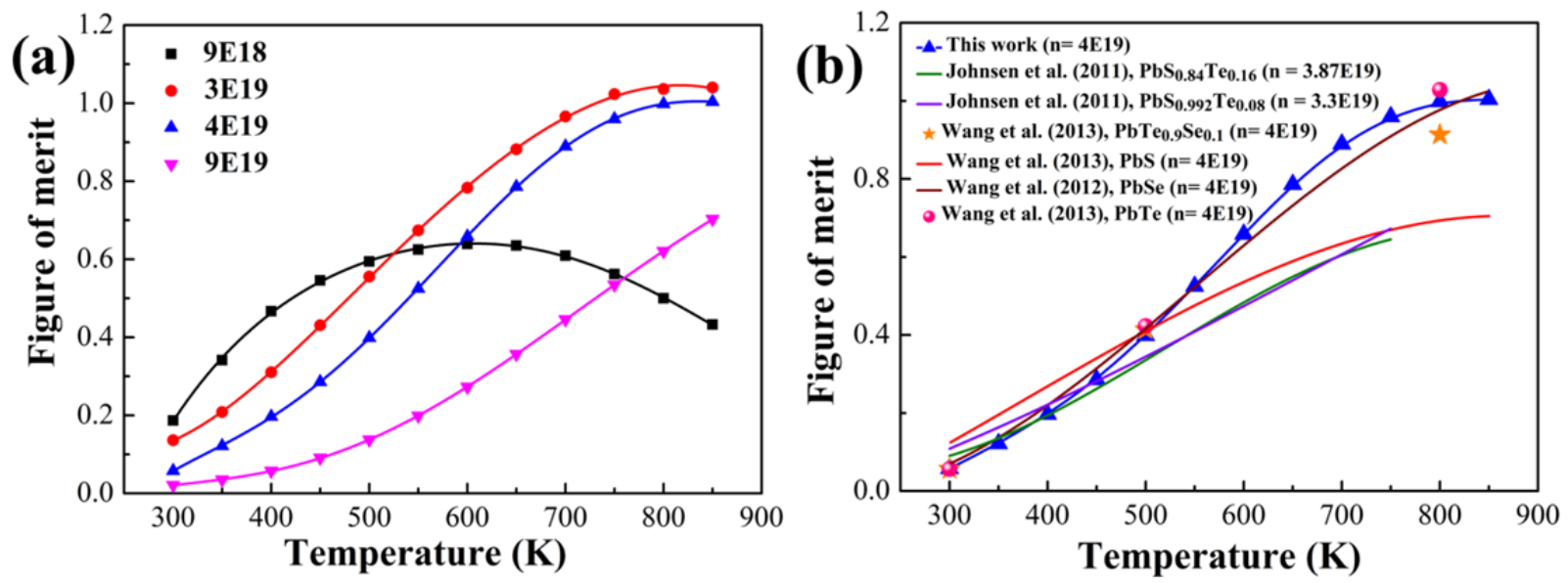

Figure 5. Temperature dependence of the figure of merit of (a) Cl-doped $(\mathrm{PbTe})_{0.75}(\mathrm{PbS})_{0.15}(\mathrm{PbSe})_{0.1}$ sintered bulk samples, and (b) $n$-type $\mathrm{PbS}_{0.15} \mathrm{Se}_{0.1} \mathrm{Te}_{0.75}$ compound at $4 \times 10^{19} \mathrm{~cm}^{-3}$ carrier density compared with reported values for $n$-type $\mathrm{PbS},{ }^{25} \mathrm{PbSe},{ }^{28}$ $\mathrm{PbTe}^{31}(\mathrm{PbTe})_{0.9}(\mathrm{PbSe})_{0.1},{ }^{31}(\mathrm{PbS})_{0.92}(\mathrm{PbTe})_{0.08}{ }^{26}$ and $(\mathrm{PbS})_{0.84}(\mathrm{PbTe})_{0.16}{ }^{26}$ at similar carrier concentration, indicating similar efficiency to $\mathrm{PbTe}, \mathrm{PbSe}$ and their alloys.

\section{CONCLUSION}

In summary, the nanostructured quaternary $n$-type $(\mathrm{PbTe})_{0.75}(\mathrm{PbS})_{0.15}(\mathrm{PbSe})_{0.1}$ composite demonstrates a maximum $z \mathrm{~T}$ of $1.1 \pm 0.2$ at $800 \mathrm{~K}$. This is similar to the thermoelectric efficiency of $n$-type binary $\mathrm{PbTe}, \mathrm{PbSe}$ and ternary $\mathrm{PbTe}-\mathrm{PbSe}$ alloys at similar carrier concentrations and higher than those of $\mathrm{PbS}$ and $\mathrm{PbS}-\mathrm{PbTe}$ compounds. A very low lattice thermal conductivity was obtained compared with those of the parent single phase alloys. This is due to phonon scattering at solute atoms, defects and interfaces originating from the 
distributed sulphide secondary phase, is compensated by low carrier mobility originated from scattering of electrons. It suggests that the nanostructured $n$-type PbTe-rich lead chalcogenides that contain precipitates as large as $100 \mathrm{~nm}$ with incoherent interfaces with the matrix do not provide thermoelectric efficiencies that are superior to those of single phase compounds. Nevertheless, additional study will be required to fully realize the effect of various precipitates morphologies on electronic transport properties of this quaternary system composite.

\section{AUTHOR INFORMATION}

\section{Corresponding Author}

*Sima Aminorroaya Yamini, Australian Institute for Innovative Materials, University of Wollongong, Innovation Campus, North Wollongong, NSW, 2519, Australia, email: sima@uow.edu.au.

*G Jeffrey Snyder, Materials Science, California Institute of Technology, Pasadena, CA 91125, USA, email: jsnyder@caltech.edu.au.

\section{Author Contributions}

All authors have given approval to the final version of the manuscript.

\section{ACKNOWLEDGMENT}

This work is supported by Australian Research Council (ARC) Discovery Early Career Award DE130100310, the Department of Education, Science and Technology (DEST) of Australia, the Air Force Office of Scientific Research - Multidisciplinary Research Program of the University Research Initiative (AFOSR-MURI) and Russian Ministry of Education.

\section{REFERENCES}

1. Bell, L. E., Cooling, Heating, Generating Power, and Recovering Waste Heat with Thermoelectric Systems. Science 2008, 321, 1457-1461. 
2. Rowe, D. M., Thermoelectrics and its Energy Harvesting. CRC Press, London: 2012.

3. Shi, X.; Yang, J.; Bai, S.; Yang, J.; Wang, H.; Chi, M.; Salvador, J. R.; Zhang, W.; Chen, L.; Wong-Ng, W., On the Design of High-Efficiency Thermoelectric Clathrates through a Systematic Cross-Substitution of Framework Elements. Adv. Funct. Mater. 2010, $20,755-763$.

4. Shi, X.; Yang, J.; Salvador, J. R.; Chi, M.; Cho, J. Y.; Wang, H.; Bai, S.; Yang, J.; Zhang, W.; Chen, L., Multiple-filled Skutterudites: High Thermoelectric Figure of Merit through Separately Optimizing Electrical and Thermal Transports. J. Am. Chem. Soc. 2011, $133,7837-7846$.

5. Pei, Y.; Shi, X.; LaLonde, A.; Wang, H.; Chen, L.; Snyder, G. J., Convergence of Electronic Bands for High Performance Bulk Thermoelectrics. Nature 2011, 473, 66-69.

6. Heremans, J. P.; Jovovic, V.; Totiberer, E. S.; Saramat, A.; Kurosaki, K.; Charoenphakdee, A.; Yamanaka, S.; Snyder, G. J., Enhancement of Thermoelectric Efficiency in PbTe by Distortion of the Electronic Density of States. Science 2008, 321, 554557.

7. $\quad$ Biswas, K.; He, J.; Zhang, Q.; Wang, G.; Uher, C.; Dravid, V. P.; Kanatzidis, M. G., Strained Endotaxial Nanostructures with High Thermoelectric Figure of Merit. Nature Chem. 2011, 3, 160-166.

8. Božin, E. S.; Malliakas, C. D.; Souvatzis, P.; Proffen, T.; Spaldin, N. A.; Kanatzidis, M. G.; Billinge, S. J. L., Entropically Stabilized Local Dipole Formation in Lead Chalcogenides. Science 2010, 330, 1660-1663. 
9. Biswas, K.; He, J.; Blum, I. D.; Wu, C.-I.; Hogan, T. P.; Seidman, D. N.; Dravid, V. P.; Kanatzidis, M. G., High Performance Bulk Thermoelectrics with All-Scale Hierarchical Architectures. Nature 2012, 489, 414-418.

10. Levin, E. M.; Bud'ko, S. L.; Schmidt-Rohr, K., Enhancement of Thermopower of TAGS-85 High-Performance Thermoelectric Material by Doping with the Rare Earth Dy. Adv. Funct. Mater. 2012, 22, 2766-2774.

11. Levin, E. M.; Cook, B. A.; Harringa, J. L.; Bud'ko, S. L.; Venkatasubramanian, R.; Schmidt-Rohr, K., Analysis of Ce- and Yb-Doped TAGS-85 Materials with Enhanced Thermoelectric Figure of Merit. Adv. Funct. Mater. 2011, 21, 441-447.

12. LaLonde, A. D.; Pei, Y.; Snyder, G. J., Reevaluation of PbTe1-xIx as High Performance n-type Thermoelectric Material. Energy Environ. Sci. 2011, 4, 2090-2096.

13. Jaworski, C. M.; Heremans, J. P., Thermoelectric Transport Properties of the $n$-type Impurity $\mathrm{Al}$ in PbTe. Phys. Rev. B 2012, 85, 033204.

14. Pei, Y.; LaLonde, A.; Iwanaga, S.; Snyder, G. J., High Thermoelectric Figure of Merit in Heavy Hole Dominated PbTe. Energy Environ. Sci. 2011, 4, 2085-2089.

15. Heremans, J. P.; Wiendlocha, B.; Chamoire, A. M., Resonant Levels in Bulk Thermoelectric Semiconductors. Energy Environ. Sci. 2012, 5, 5510-5530.

16. Pei, Y.; LaLonde, A. D.; Heinz, N. A.; Shi, X.; Iwanaga, S.; Wang, H.; Chen, L.; Snyder, G. J., Stabilizing the Optimal Carrier Concentration for High Thermoelectric Efficiency. Adv. Mater. 2011, 23, 5674-5678.

17. Lee, Y.; Lo, S.-H.; Androulakis, J.; Wu, C.-I.; Zhao, L.-D.; Chung, D.-Y.; Hogan, T. P.; Dravid, V. P.; Kanatzidis, M. G., High-Performance Tellurium-Free Thermoelectrics: All- 
Scale Hierarchical Structuring of p-Type PbSe-MSe Systems $(\mathrm{M}=\mathrm{Ca}, \mathrm{Sr}, \mathrm{Ba}) . J$ Am. Chem. Soc. 2013, 135, 5152-5160.

18. Ahn, K.; Biswas, K.; He, J.; Chung, I.; Dravid, V.; Kanatzidis, M. G., Enhanced Thermoelectric Properties of $p$-type Nanostructured PbTe-MTe $(\mathrm{M}=\mathrm{Cd}, \mathrm{Hg})$ Materials. Energy Environ. Sci. 2013, 6, 1529-1537.

19. Zhao, L.-D.; He, J.; Wu, C.-I.; Hogan, T. P.; Zhou, X.; Uher, C.; Dravid, V. P.; Kanatzidis, M. G., Thermoelectrics with Earth Abundant Elements: High Performance $p$-type PbS Nanostructured with SrS and CaS. J. Am. Chem. Soc. 2012, 134, 7902-7912.

20. Pei, Y.; Wang, H.; Gibbs, Z. M.; LaLonde, A. D.; Snyder, G. J., Thermopower Enhancement in $\mathrm{Pb}_{1-\mathrm{x}} \mathrm{Mn}_{\mathrm{x}}$ Te Alloys and its Effect on Thermoelectric Efficiency. NPG Asia Materials 2012, 4.

21. Rogers, L. M.; Crocker, A. J., Transport and optical properties of the $\mathrm{Mg}_{\mathrm{x}} \mathrm{Pb}_{1-}{ }_{\mathrm{x}} \mathrm{Te}$ Alloy Aystem. J. Phys. D: Appl. Phys. 1971, 4, 1016.

22. Crocker, A. J.; Sealy, B. J., Some Physical Properties of the PbTe-MgTe Alloy System. J. Phys. Chem. Solids 1972, 33, 2183-2190.

23. Crocker, A. J.; Rogers, L. M., Valence Band Structure of PbTe. J. Phys. Colloq. 1968, 29, 129-132.

24. Aminorroaya Yamini, S.; Wang, H.; Gibbs, Z.; Pei, Y.; Dou, S. X.; Snyder, G. J., Chemical Composition Tuning in Quaternary p-type Pb-Chalcogenides - A Promising Strategy for Enhanced Thermoelectric Performance. Phys. Chem. Chem. Phys. 2014, 16, $1835-1840$ 
25. Wang, H.; Schechtel, E.; Pei, Y.; Snyder, G. J., High Thermoelectric Efficiency of $n-$ type PbS. Adv. Energy Mater. 2012, 3, 488-495.

26. Johnsen, S.; He, J.; Androulakis, J.; Dravid, V. P.; Todorov, I.; Chung, D. Y.; Kanatzidis, M. G., Nanostructures Boost the Thermoelectric Performance of PbS. J Am. Chem. Soc. 2011, 133, 3460-3470.

27. Zhao, L.-D.; Lo, S.-H.; He, J.; Li, H.; Biswas, K.; Androulakis, J.; Wu, C.-I.; Hogan, T. P.; Chung, D.-Y.; Dravid, V. P.; Kanatzidis, M. G., High Performance Thermoelectrics from Earth-Abundant Materials: Enhanced Figure of Merit in $\mathrm{PbS}$ by Second Phase Nanostructures. J Am. Chem. Soc. 2011, 133, 20476-20487.

28. Wang, H.; Pei, Y.; Lalonde, A. D.; Snyder, G. J., Weak Electron-Phonon Coupling Contributing to High Thermoelectric Performance in $n$-type PbSe. Proc. Natl. Acad. Sci. U.S.A. 2012, 109, 9705-9.

29. Evola, E. G.; Nielsen, M. D.; Jaworski, C. M.; Jin, H.; Heremans, J. P., Thermoelectric Transport in Iindium and Aluminum-Doped Lead Selenide. Journal of Applied Physics 2014, 115, -.

30. Androulakis, J.; Todorov, I.; He, J.; Chung, D.-Y.; Dravid, V.; Kanatzidis, M., Thermoelectrics from Abundant Chemical Elements: High-Performance Nanostructured PbSe-PbS. J. Am. Chem. Soc. 2011, 133, 10920-10927.

31. Wang, H.; LaLonde, A. D.; Pei, Y.; Snyder, G. J., The Criteria for Beneficial Disorder in Thermoelectric Solid Solutions. Adv. Funct. Mater. 2012, 23, 1586-1596.

32. Zhao, L.-D.; Hao, S.; Lo, S.-H.; Wu, C.-I.; Zhou, X.; Lee, Y.; Li, H.; Biswas, K.; Hogan, T. P.; Uher, C.; Wolverton, C.; Dravid, V. P.; Kanatzidis, M. G., High Thermoelectric 
Performance via Hierarchical Compositionally Alloyed Nanostructures. J Am. Chem. Soc. 2013, $135,7364-7370$.

33. Aminorroaya Yamini, S.; Wang, H.; Gibbs, Z.; Pei, Y.; David Mitchel; Dou, S. X.; Snyder, G. J., Thermoelectric Performance of Tellurium-Reduced Quaternary $p$-type LeadChalcogenide Composites. Unpublished manuscript 2014.

34. Androulakis, J.; Lee, Y.; Todorov, I.; Chung, D.-Y.; Kanatzidis, M., HighTemperature Thermoelectric Properties of $n$-type PbSe Doped with Ga, In, and Pb. Phys. Rev. B 2011, 83, 195209.

35. LaLonde, A. D.; Ikeda, T.; Snyder, G. J., Rapid Consolidation of Powdered Materials by Induction Hot Pressing. Rev. Sci. Instrum. 2011, 82, 025104.

36. Borup, K. A.; Toberer, E. S.; Zoltan, L. D.; Nakatsukasa, G.; Errico, M.; Fleurial, J.P.; Iversen, B. B.; Snyder, G. J., Measurement of the Electrical Resistivity and Hall Coefficient at High Temperatures. Rev. Sci. Instrum. 2012, 83, 123902-7.

37. Volykhov, A.; Yashina, L.; Shtanov, V., Phase Relations in Pseudobinary Systems of Germanium, Tin, and Lead Chalcogenides. Inorg. Mater. 2006, 42, 596-604.

38. Volykhov, A.; Yashina, L.; Shtanov, V., Phase Equilibria in Pseudoternary Systems of IV-VI Compounds. Inorg. Mater. 2010, 46, 464-471.

39. Ravich, Y. I.; Efimova, B. A.; Smirnov, I. A., Semiconducting lead chalcogenides Plenum Press in New York: 1970.

40. Gibbs, Z. M.; Kim, H.; Wang, H.; White, R. L.; Drymiotis, F.; Kaviany, M.; Jeffrey Snyder, G., Temperature Dependent Band Gap in $\mathrm{PbX}(\mathrm{X}=\mathrm{S}, \mathrm{Se}, \mathrm{Te})$. Applied Physics Letters 2013, 103, 262109. 
41. Rowe, D. M., CRC handbook of thermoelectrics. CRC Press LLC: 1995.

42. May, A. F.; Toberer, E. S.; Saramat, A.; Snyder, G. J., Characterization and Analysis of Thermoelectric Transport in $n$-type $\mathrm{Ba}_{8} \mathrm{Ga}_{(16-\mathrm{x})} \mathrm{Ge}_{(30+x)}$. Phys. Rev. B 2009, 80, 125205.

43. Wang, H.; Wang, J.; Cao, X.; Snyder, G. J., Thermoelectric Alloys Between PbSe and $\mathrm{PbS}$ with Effective Thermal Conductivity Reduction and High Figure of Merit. J. Mater. Chem. A 2014, 2, 3169-3174.

44. Chasmar, R. P.; Stratton, R., The Thermoelectric Figure of Merit and its Relation to Thermoelectric Generators. J. Electron. \& Contr. 1959, 7, 52-72.

45. Goldsmid, H. J., Introduction to Thermoelectricity. Springer, Berlin, Heidelberg: 2010.

46. Wang, H.; Pei, Y.; LaLonde, A. D.; Snyder, G. J., Material Design Considerations Based on Thermoelectric Quality Factor. In Thermoelectric Nanomaterials-Materials Design and Applications, Koumoto, K.; Mori, T., Springer, Heidelberg: 2013. 